$\begin{array}{cc}\text { Programa de Pós-Graduação em Engenharia de Produção - PPGEP } & \\ \text { Laboratório de Qualidade de Vida - LaQVida } & \text { REVISTA BRASILEIRA DE } \\ \text { Universidade Tecnológica Federal do Paraná - UTFPR } & \text { Ponta Grossa - PR - Brasil } \\ \text { v. 01, n. 02, jul./dez. } 2009 \text {, p. } 01-07 & \text { QUALIDADE DE VIDA }\end{array}$

DOI: $10.3895 /$ S2175-08582009000200001

\title{
Patologias sociais e a qualidade de vida na sociedade moderna
}

\author{
Social pathologies and quality of life in modern society
}

\author{
Marco Antonio Bettine de Almeida \\ Universidade de São Paulo - USP - Ribeirão Preto - Brasil \\ marcobettine@usp.br \\ Luís Fernando Vitagliano \\ Universidade Estadual de Campinas - Unicamp - Campinas - Brasil \\ luisvita@unicamp.br
}

\begin{abstract}
Resumo
Este artigo tem como objetivo estudar alguns elementos das patologias sociais, relacionando-os aos modos de vida na sociedade moderna, principalmente sobre a ótica do trabalho. Discute-se a questão do tempo, da racionalização como mecanismos que tendem a gerar as fadigas dentro do mundo do trabalho e da vida. A força do mundo do trabalho acaba por integrar o modelo de vida em todas as esferas sociais, provocando uma racionalização nos momentos de não trabalho. Estes mecanismos geram mais stress e fortalecem as patologias sociais. Para sair deste processo autofágico propõem-se a utilização do esporte como aliviador dos sintomas relacionados aos Transtornos Mentais Comuns como possibilidade de atuação imediata neste problema social concreto.
\end{abstract}

Palavras-chave: Patologias Sociais, Transtornos Mentais Comuns (TMC), Qualidade de Vida, Sociedade Industrial, Esporte e Desenvolvimento Social.

\begin{abstract}
This article aims to study some elements of social pathologies, relating them to the ways of life in modern society, especially from the standpoint of work. It discusses the issue of time, streamlining mechanisms that tend to generate the fatigue in the world of work and life. The strength of the working world eventually incorporate the model of life in all social spheres, leading to a rationalization in times of no work. These mechanisms generate more stress and strengthen social pathologies. To unsubscribe from this process autophagic propose to use sport as a reliever of the symptoms related to Common Mental Disorders as the possibility of immediate action in this particular social problem.
\end{abstract}

Keywords: social pathologies, Common Mental Disorders (CMD), Quality of Life, Industrial Society, Sports and Social Development.

\section{Introdução}

As patologias sociais têm afetado tanto a qualidade de vida dos cidadãos como as doenças comuns. Entendamos como patologias sociais os processos de adoecimento que tem origem na rotina ou modo de vida da população. Podemos qualificar como patologia social todos os 
Transtornos Mentais Comuns (TMC), como o stress, por exemplo, que pode ser decorrente de uma determinada condição de vida e/ou estilo de vida. Assim como as mais diversas formas de depressão. Outros transtornos menos identificáveis são alguns dos ataques cardiovasculares e a obesidade.

Dada esta constatação, surge uma contradição inerente aos processos de diagnóstico e proposta de tratamentos, porque, se parte significativa dos problemas identificados como patologias hoje são oriundos do comportamento social e/ou da vida em grandes cidades, esta origem - o mal combatível - não está em determinantes fisiológicos, mas na falta de qualidade de vida. Portanto, quando a população em geral procura um médico com sintomas decorrentes de problemas que surgem devido a rotinas exaustivas, recorrentemente as respostas são fisiológicas, com tratamentos bioquímicos. Ou seja, o tratamento baseado em remédios agride os sintomas dos problemas apresentados, mas não arremata suas causas que têm origens sociais e não somente biológicas.

Publicações na área médica associam os problemas de saúde decorrentes com o comportamento social. Ludemir (2008), discute a correlação entre desemprego, informalidade e agravamento das TMCs:

\begin{abstract}
Alguns autores sugerem que, para a saúde mental, os efeitos das dificuldades crônicas são mais importantes que os eventos vitais produtores de estresse. No entanto, Weich e Lewis (1998) encontraram resultados opostos e as dificuldades financeiras no momento das entrevistas mostraram-se associadas com a incidência e a prevalência dos TMC, enquanto a pobreza esteve apenas associada à manutenção dos episódios. Para Lewis (1996) e Wilkinson (1996), a falta de dinheiro pode levar ao estresse e à insegurança, mecanismos psicológicos causadores dos TMC. Wilkinson (1997) sugere, no entanto, que pelo menos nos países desenvolvidos, as desigualdades de renda (pobreza relativa) comprometem mais a saúde do que as precárias condições de vida (pobreza absoluta), afirmando também que a tomada de consciência sobre as desigualdades socioeconômicas afeta a saúde mental (LUDEMIR, 2008, p. 454).
\end{abstract}

Hoje, com o avanço da medicina social já é possível defender que o TMC tem origem social, será que é plausível, também, levantar a hipótese de que outras patologias consideradas clínicas são de ordem sociológica? A pergunta que nos estimula se resume na seguinte sentença: por que tratar doenças ligadas à qualidade de vida com medicamentos se o problema está no cotidiano, na forma de encaminhar a qualidade de vida, nas dificuldades de relacionamento? Se o problema é social porque a resposta deve ser fisiológica?

Um caso paradigmático poderá elucidar estas questões suscitadas.

Existe relação entre o aumento do uso de antidepressivos e infartos? Será que antidepressivo provoca infarto? A resposta pode simplesmente ser: o antidepressivo combate os sintomas dos problemas que o stress e o efeito da pressão cotidiana descarregam nas pessoas e ao "mascarar" sintomas, temos que esses efeitos acabam perdendo seu aspecto de processo de desenvolvimento de uma patologia e sobrecarregam o corpo até que entre em blackout.

Os médicos poderiam reagir afirmando que não existem dados que associem o uso de antidepressivos ao infarto, por exemplo. Mas, não é absurdo relacionar que existe uma correlação entre o uso de antidepressivo e infarto, sendo que ambos podem ter uma mesma origem: quando se trata de um problema de ordem rotineira que sobrecarrega o sistema nervoso e se combate com antidepressivo, remedia-se os sintomas do problema e não seu fator detonador. A sequiência: depressivo-infarto, não significa necessariamente uma relação de causa e efeito, mas pode-se supor uma ação diagnóstica em sintomas e não em causas que dependendo dos casos pode levar ao infarto.

Não se quer com isso supor que há erro médico em determinadas circunstâncias de tratamento com antidepressivo ou na apresentação de diagnósticos, apenas sugerir que determinadas questões mais gerais como a racionalização da sociedade pode estar na origem de problemas considerados físicos. Mas, defender que há uma tendência da sociedade em adiar os problemas originários da rotina desordenada e prejudicial à qualidade de vida com tratamentos que levam em consideração apenas os sintomas dos problemas e não suas causas não é nenhum equívoco. 
Se a hipótese deste artigo está correta, é o cotidiano que gera perda da qualidade de vida dos cidadãos e é isso que tem recaído como uma série de problemas que são camuflados pelo uso de medicamentos ${ }^{1}$. Esses medicamentos corrigem as disfunções fisiológicas, mas não atingem as origens dos problemas. Dramática a situação porque não se trata de um problema isolado, mas de condições de vida típico da sociedade moderna e que não se limita ao Brasil.

\section{A questão do trabalho e o uso do tempo}

O mundo do trabalho interfere na saúde doi trabalhador. Os diversos estudos sobre a fadiga mostram que há um ajuste fisiológico do ser humano com os equipamentos da fábrica. Os estudos sobre o movimento repetitivo do fordismo tiveram efeito na produtividade, como também no desempenho bioquímico dos trabalhadores. Basta atentar para os casos de lesões por esforço repetitivo (LER) que passaram a fazer parte das doenças relacionadas ao trabalho.

Os movimentos estudados por engenheiros é um processo antigo. Taylor realizou uma revolução gerencial dentro da organização fabril já no início do século XX. Sua forma de otimizar o tempo e orientar o processo fabril transformou-se em uma "escola de pensamento". A rotina é um movimento involuntário e tão sutil que seus efeitos são sentidos apenas ao longo dos anos. Uma rotina mal formada, não acompanha a evolução do desgaste do corpo, sem o adequado acompanhamento biofísico causa seqüelas incuráveis. Agora, acrescente isso ao ritmo intenso de trabalho e de vida em cidades grandes. Com o aumento da idade, na medida em que o corpo se desgasta, a rotina caminha em sentido oposto, torna-se mais severa e penosa. É inevitável que o corpo passe por transformações fisiológicas que o deixem menos resistente.

Nos anos 1920 e 1930, várias experiências foram registradas para avaliar o desempenho de trabalhadores no chão de fábrica. São as famosas "experiências de Hawthorne": A luz tem efeito na produtividade? A divisão do espaço interfere na produção? O comando faz diferença? O que dizer dos processos de cooperação e identidade do trabalhador? Independente da importância que esses estudos tiveram para o cálculo da fadiga e da produtividade, os teóricos da administração chegaram à conclusão de que os fatores psicológicos são mais importantes que os fisiológicos na produtividade do trabalho. Assim surge toda uma corrente ligada a administração de empresas que justifica a necessidade de trabalhar o "capital humano".

Concebidas por Elton Mayo a partir de 1923, várias experiências sobre o efeito dos intervalos na produtividade da industrial têxtil da Filadélfia mostraram que o uso do tempo para algum descanso mínimo é otimizador da produção. Depois disso o autor foi convidado a seguir fazendo experimentos em fábricas que tiveram efeitos importantes para os administradores pensarem no processo produtivo e nos motivos que geram a fadiga. A partir de 1927 Mayo realizou as "experiências de Hawthorne" (bairro operário de Chicago), que influenciaram na literatura sobre a divisão do trabalho e geraram várias correntes teóricas dentro das estratégias de administração e organização do trabalho. Os efeitos da fadiga tornaram-se mais conhecidos e cada vez mais se aprofundou nos estudos sobre a saúde do trabalhador.

As experiências, tanto da Filadélfia quanto de Chicago levaram Mayo a interpretar que a fadiga tem uma origem ligada a questões psicológicas mais que bioquímicas. Antes de acusar uma causa física, o organismo reage psicologicamente ao processo de cansaço (MAYO, 1933). Baseado nessas constatações, a Organização Mundial do Trabalho (OMT) fixou parte do seu aporte nas interpretações a respeito dos "recursos humanos" entendidos a partir da sua rede de relações. Ao tratar deste tema, as questões da administração do trabalho se voltaram para conceitos como motivação, pressão, metas, estímulos, liderança e equipe.

\footnotetext{
${ }^{1}$ Apesar do monitoramento da JIFE (Junta Internacional de Fiscalização de Entorpecentes), o uso de antidepressivo tem crescido mundialmente. No Brasil, o uso de antidepressivo esta em franca expansão entre a classe média. A automedicação se torna outro problema, o jogo em que tudo vale a pena para se sentir melhor passa a ser uma forma de adiar problemas que exigem uma solução mais drástica e penosa.
} 
Esta "engenharia social" oriunda das experiências de produtividade descartou os efeitos fisiológicos que os movimentos repetitivos podem causar. Em conseqüência a vasta bibliografia sobre "estudos do movimento" e os efeitos da ciência do treinamento, desenvolvida na área do esporte nunca foi de interesse do administrador e jamais atingiram o efeito prático ao participar do "chão de fábrica"2.

É evidente que o corpo tem elasticidade para adaptar-se aos processos de trabalho, e está alheio a algum desgaste. Porém, no longo prazo, os movimentos que testam os limites da exaustão foram negligenciados. Desde a imposição do taylorismo e do fordismo no mundo do trabalho, pouco se contribuiu para a análise das conseqüências dos movimentos no processo de trabalho do operário. Agora, cada vez menos o corpo é importante ao trabalho e cada vez mais os processos de raciocínio tornam-se indispensáveis para a produtividade. E novamente os efeitos da fadiga mental têm pouca expressão nos cálculos de produtividade. As questões biológicas não são tratadas no âmbito produtivo e não fazem parte da preparação destinada pelos empresários aos seus trabalhadores. Além disso, outro efeito desse descolamento - o desgaste do trabalhador - pode ser visualizado pelo crescimento de uma série de patologias antes escassas (TMC).

Portanto, ao determinar a questão do stress ou depressão na esfera da psiquiatria, a ciência da administração se eximiu de pensá-las como decorrentes dos ambientes de trabalho, tratando-as como casos isolados e particulares de indivíduos que precisam de medicamentos.

Supondo que o perfil do trabalhador moderno usa mais o raciocínio que a força física, como retirar disso estratégias e treinamentos para elevar a produtividade? Onde a qualidade de vida pode auxiliar? E mais: como minimizar os impactos dos danos provocados pela fadiga?

As necessidades de produção pouco se atentam para os sintomas de desgaste e/ou fadiga. Percebeu-se que ao estimular o trabalhador (ou pressioná-lo para manter a produção), o que faz diferença é seu empenho psicológico e não sua postura fisiológica. Porém, a fadiga acontece com o tempo. Assim, é normal que o trabalhador busque nos remédios um refúgio para evitar que a exaustão interfira no processo de produtividade.

Mas, o que faz o remédio? Adia o problema. Faz com que os sintomas da fadiga desapareçam. Por outro lado, as causas que levaram aos sintomas continuam a atuar; só não se convertem em empecilhos para a continuidade do trabalho. Os sintomas escondem o agravamento do problema e os colapsos podem ser inevitáveis - quando não, ocorre a dependência dos medicamentos.

\section{3. $\mathrm{O}$ paradigma do trabalho transposto à cultura moderna}

O trabalho estabelece padrões, organiza pensamentos e invade a vida cotidiana de forma a interferir na cultura. $\mathrm{O}$ trabalho disciplina o tempo e o uso do tempo vai para além do mundo do trabalho. Edward Palmer Thompson tem um artigo seminal sobre "tempo, disciplina de trabalho e capitalismo industrial" ", onde discute o uso do tempo pelo trabalhador, disciplinado a vender parte de seu dia ao patrão. A disciplina com que se entrega a força de trabalho apresenta conseqüências, mas, também, o uso que se faz do tempo é fundamental para discutir a qualidade de vida. Quanto tempo passa-se no trânsito? Quanto tempo se usa para dormir? Quanto tempo se dedica ao lazer? E, quanto tempo trabalha-se?

Se o trabalho induz ao uso disciplinado e eficiente do tempo, porque não acreditar que fora do trabalho as pessoas não querem usar de forma racional também o tempo de lazer. Portanto, trabalhar-se-á com o suposto segundo o qual o tempo fora do trabalho ganha racionalidade similar ao tempo disciplinado pelo trabalho. Neste sentido, a cultura sofre interferência da sociedade industrial dando ao homem moderno um novo patamar de comportamento cotidiano.

\footnotetext{
${ }^{2}$ O Máximo que o esporte transmitiu ao empresário nesta área de atuação direta na manufatura (produção, produtividade eficiência, eficácia etc) foi a ginástica laboral, que não tem ligação direta com a fabricação de produtos e não entra em seu cálculo. Muito pouco para mais de meio século de progresso e construção de conhecimento a respeito do corpo humano.

${ }^{3}$ In: THOMPSON, Edward Palmer. Costumes em comum. São Paulo: Companhia das Letras, 1998; p. 267-304.
} 
A incorporação dos hábitos do ambiente de trabalho em todos os momentos de vida das pessoas, resumidamente, a racionalização das ações sociais, no sentido mais amplo, integra-se em diferentes mecanismos de ação que perpassam o universo simbólico no qual o agente vive, onde o corpo é o primeiro filtro da percepção seja através dos sentidos, ou compreendido como experiências.

Pode-se pensar que no trabalho há um processo de racionalização da vida, ocorre uma perda de liberdade nos processos de burocratização que acompanhavam e permitiam o desenvolvimento de níveis cada vez mais complexos de organização social (HABERMAS, 1989, p. 352). Primeiramente o trabalho degenerava o corpo, agora interfere no espírito.

Estes fatores, identificado por Habermas, via Weber, como processos de secularização ou de desencantamento das visões de mundo, e conseqüente diferenciação/autonomização das esferas culturais de valor, leva a uma perda de significado da vida em sociedade (HABERMAS, 1987, p. $350)$.

Numa sociedade industrial a cultura da fábrica, do escritório, do trabalho especializado e padronizado se torna lugar comum do comportamento cidadão. Baseados em trabalho assalariado e especialização das funções o homem moderno não se identifica com o produto do seu trabalho, mas racionaliza sua função ao buscar resultados e não os processos de fabricação. Submete suas decisões ao tempo e o tempo à busca de resultados. Se alguém faz isso na maior parte do seu tempo durante a semana e considera isso como "tempo útil" - tempo de trabalho -, em oposição ao "tempo inútil" - o tempo do lazer - por que não supor que se racionalizaria também o "tempo inútil" para otimizar seus resultados?

\section{O papel do exercício físico para a qualidade de vida: o valor do esporte}

A noção de qualidade de vida transita em um campo semântico e polissêmico: de um lado, está relacionada ao modo, condições e estilos de vida. De outro, inclui as idéias de construção humana e valores socialmente constituídos. E, por fim, relaciona-se ao campo da democracia, do desenvolvimento e dos direitos humanos e sociais. No que concerne à saúde, as noções se unem em uma resultante social da construção coletiva dos padrões de conforto e tolerância que determinada sociedade estabelece como parâmetros para si (ALMEIDA; GUTIERREZ; MARQUES, 2009, p. 8).

Pensar qualidade de vida é relacionar a noção, o entendimento e a construção histórica, com os sentimentos psíquicos da população na vida familiar, amorosa, social e ambiental. O conteúdo social, relacional e cultural que envolve desde o acesso aos bens materiais até o uso destes bens. Perceber os significados da qualidade de vida é o compreender como construção cultural.

Todavia, se a sociedade moderna baseia parte significativa da sua construção cultural com base na eficiência laboral, a qualidade de vida, entre outras coisas, age para garantir a produtividade trabalhadora em harmonia. Se assim se faz, a atividade física perde significado social em si e passa a ser um meio para atingir melhor desempenho produtivo.

Neste caso, o esporte, mais que a atividade física, ganha prioridade entre as funções da educação do corpo. O esporte tem mais "afinidade" que qualquer outra função junto ao homem contemporâneo. Porque o esporte trabalha com conceitos caros à atividade empresarial, como: eficiência, eficácia, otimização, planejamento e busca por resultados.

O esporte desempenha um importante papel na formação do homem moderno e da vida em sociedade. Passou-se a discursar sobre o esporte como sendo matriz de socialização e transmissão de valores, forma de sociabilidade, instrumento de educação e fonte de saúde. Pergunta-se: qual esporte? Como as pessoas praticam as modalidades esportivas?

Aos saudáveis que praticam algum tipo de modalidade esportiva, ainda que sem o padrão competitivo, afirma-se que se afastam os males atuais como obesidade, hipertensão, problemas cardiovasculares ou também o stress.

Fica claro nas questões levantada acima que o esporte pode ser praticado como mero discurso reproduzindo o aspecto racionalizador da sociedade moderna, ou utilizá-lo como estratégia 
de ação frente às patologias sociais, ou melhor, transformando as condições de vida que somos submetidos em uma sociedade altamente burocratizada e racionalizadora.

O esporte sempre exige um cálculo. Cálculo inclusive de utilidade. Praticar a atividade física esportiva, mais que qualidade de vida, avalia desempenho. Requer melhora. Para melhorar há necessidade de planejamento. Busca-se otimização do tempo. Recurso tão escasso na sociedade atual. $\mathrm{O}$ esporte racionaliza o desempenho do seu praticante e busca progresso. Portanto, ao recorrer a termos tão presentes no mundo do trabalho pode causar a impressão de que o tempo "inútil" ganha determinada utilidade ao usar-se desses termos para tratar a atividade extra-laboral.

Pode-se, portanto, utilizar como estratégia esta visão do esporte na sociedade como algo útil e que trás benefícios práticos na vida das pessoas (diminui o stress, alivia a tensão, combate a obesidade, deixa a pessoa mais sexy, entre outros atributos), para conseguir nas intervenções aliviar as patologias sociais. Neste caso propõem-se não somente uma atitude de praticar modalidades esportivas ou exercícios, mas voltar estas ações com os objetivos da qualidade de vida, mais do que promover práticas esportivas deve-se estruturar os objetivos da prática, afastando o modelo de performances e incorporando o modelo de qualidade de vida.

Ao desenvolver um programa de atividade física é preciso considerar não somente os benefícios fisiológicos do mesmo, mas também buscar atender a outros níveis de exigência do ser humano. Tais níveis dizem respeito a necessidades de relacionamento, bem-estar e auto-estima. A prática esportiva se apresenta como uma dessas possibilidades, pois o esporte é um fenômeno social que além de incentivar a atividade física, promove interação social e influencia no relacionamento entre os participantes.

Porém, a simples ocorrência de atividades esportivas não garante que seja desenvolvido um sentimento de integração entre colegas, a identificação com o local de trabalho, o desenvolvimento da individualidade e auto-estima do empregado. É importante que haja, por parte dos organizadores de atividades esportivas, conhecimento específico a respeito dos valores e das formas de manifestação do esporte (MARQUES; GUTIERREZ; ALMEIDA, 2008).

Num ambiente em que as atividades esportivas e de lazer são pautadas em normas do altorendimento, valores como o individualismo, a rivalidade e a segregação podem vir a ser transmitidos, pois esse modelo valoriza os vencedores em detrimento dos perdedores. Já a prática esportiva pautada na qualidade de vida sugere ações cooperativas em suas atividades, visto que o objetivo é promover um processo de atividade esportiva independente da nomeação de melhores ou piores, vencedores e perdedores.

Uma das questões pertinentes à qualidade de vida é a relevância de alguns níveis de exigência do ser humano, como necessidade de relacionamento, bem-estar no ambiente de trabalho e manutenção de sua auto-estima. Ao adotar programas de qualidade de vida, a empresa deve atentar para as atividades que estão sendo propostas e como estão sendo aplicadas. O esporte é uma forma de atividade física que, além de auxiliar na promoção do anti-sedentarismo e de benefícios à saúde clínica, pode incentivar formas de relacionamento saudáveis entre os participantes (MARQUES; GUTIERREZ; ALMEIDA, 2008).

Se não houver este esforço de formar profissionais com esta visão, o próprio exercício/atividade reproduzirá a sociedade racionalizadora que quantifica e mede desempenho, levando inevitavelmente a um aumento das patologias sociais.

\section{Considerações Finais}

O que a pratica esportiva tem a ensinar a sociedade moderna? Acusamos aqui o fato de o esporte herdar, de certa forma, conceitos e contextos oriundos da sociedade industrial. Todavia, deve-se fazer justamente o caminho inverso neste momento. $\mathrm{O}$ que a sociedade industrial pode aprender com a atividade esportiva voltada a qualidade de vida?

O esporte torna-se dentro de atividade de lazer um modus-operandi da cultura moderna, fazse útil ao mostrar que as patologias sociais são mantidas sem que os sintomas sejam afastados. O esporte tornar-se-ia uma estrutura de reconciliação do homem racional com seus limites biológicos. 
O esporte age, portanto, preventivamente. Ativa o metabolismo e amplia a capacidade fisiológica para a resistência. Aumenta, inclusive, a capacidade de trabalho e ajuda a evitar a fadiga. Se a exaustão física causada pelo trabalho for combatida antes do aparecimento dos sintomas, o esporte pode tornar-se o grande aliado do homem diante do frenesi do tempo.

Trabalhar com as questões da qualidade de vida no esporte pode ser um excelente aliado na prevenção das patologias sociais, enquanto não se reconstruir esta sociedade que cultiva os Transtornos Metais Comuns como meros desvios individuais.

\section{Referencias}

ALMEIDA, M. A. B.; GUTIERREZ, G. L.; MARQUES, R. F. R. Qualidade de Vida como objeto de estudo polissêmico: contribuições da Educação Física e do Esporte. Revista Brasileira de Qualidade de Vida. v. 01, n. 01, jan./jun. 2009, p. 15-22.

LURDEMIR, Ana B. Desigualdade de classe e gênero e saúde mental das cidades. In: Phisis Revista de Saúde Coletiva. Rio de Janeiro. v.18, n.3, p. 451-467, 2008.

HABERMAS, J. Teoria de la acción comunicativa. Madri: Taurus, vol.2, 1987.

Consciência moral e agir comunicativo. Rio de Janeiro: Tempo brasileiro, 1989.

MARQUES, Renato, GUTIERREZ, Gustavo e ALMEIDA, Marco. O esporte contemporâneo e o modelo de concepção das formas de manifestação do esporte. Conexões. v.6, n.2, p. 42-61, 2008.

MAYO, Elton. The human problems of na industrial civilization. Nova York: The Macmilan Co, 1933.

THOMPSON, E. P. Costumes em comum. São Paulo: Companhia das Letras, 1998.

WEBER, Max. Economia e sociedade: fundamentos da sociologia compreensiva. 3. ed. Brasília: Editora Universidade de Brasília, 1994. Tradução: Regis Barbosa e Karen Elsabe Barbosa. Revisão técnica: Gabriel Cohn.

Submetido em 09/09/2009. Aceito para publicação em 20/10/2009. 